\title{
Generalized Design Approach of a Family of Grid- Connected Converters Based on Active Virtual Ground Technique for Single-Phase AC Microgrid Applications
}

\author{
Ken King Man Siu and Carl Ngai Man Ho
}

\begin{abstract}
The paper presents the state-of-the-art technique Active Virtual Ground (AVG) in the design of single-phase gridconnected converters which fully covers the entire applications on AC microgrids. Based on the three main components of the microgrid, the presented topologies belonging to the AVG series are divided into three different groups, which are associated with power consumers, renewable energy, and energy storage systems. The whole series of the single-phase converters are also based on the latest AVG technique. Therefore, in each application, a corresponding single-stage AVG converter can be found, which has high efficiency, low leakage current, and continuous grid current. The topology advantages and the working principle of the AVG converter family are demonstrated through the circuit evaluation and are experimentally verified in a set of 650 to $800 \mathrm{~W}$ prototypes which shows a good agreement on between both of the experimental results and theoretical finding.
\end{abstract}

Index Terms-Grid-connected converter, leakage current, single-phase microgrid.

\section{INTRODUCTION}

$\mathrm{U}$ NDER the fast technological growth in the past decade, the industry of electronics becomes more mature. Consequently, the demands for power electronics converters are greatly increased. In an AC microgrid system [1]-[3], they act as a power interface between different electronic appliances and the AC grid. Meanwhile, they also serve to establish a connection between different renewable energy sources and the microgrid network. A typical structure of a single-phase (1P) ac microgrid system is shown in Fig. 1, in which it involves three main components which are namely Power Consumer, Renewable Energy Source (RES), and Energy Storage System (ESS). According to the needs of the application and the required specifications, different kinds of converter structure will be selected, which can be AC-DC, DC-AC, or bidirectional AC-DC designs. Therefore, the entire system has the ability to work alone as a local grid network or integrate

Manuscript received July 30, 2020; revised September 4, 2020; accepted September 8, 2020. Date of publication September 30, 2020; date of current version September 21, 2020. This work was supported by a grant from the Canada Research Chairs, Canada under Grant 950-230361.

The authors are with Renewable Energy Interface and Grid Automation Laboratory, Department of Electrical and Computer Engineering, University of Manitoba, Winnipeg, Canada (e-mail: kingman.siu@umanitoba.ca)

Digital Object Identifier 10.24295/CPSSTPEA.2020.00017

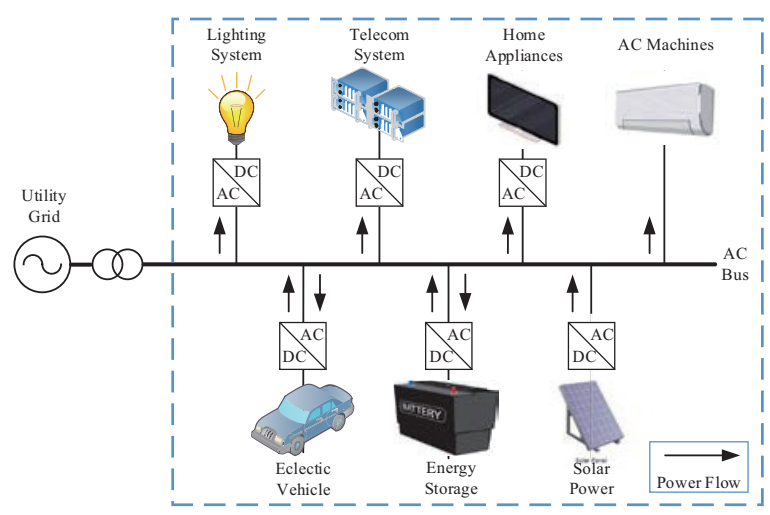

Fig. 1. Structure of a single-phase AC microgrid.

with a unity grid system, and can support direct connection with any traditional grid-connected equipment.

Recently, many fast switching devices are introduced and many new topologies are proposed. 1P grid-connected converters have become more popular and they can be seen everywhere in our daily lives, where most of them are located in a place that the general public can touch. Therefore, the requirements for converter design in different applications have also been standardized, where safety is one of the important requirements, such as IEC 62109 for photovoltaic (PV) systems [4] and IEC 60335 for household appliances [5]. To deal with system leakage current generated from the high frequency (HF) converters, variant kind of solutions were developed in the past by different researchers, such as using electronics devices to offer electrical isolation in the system [6], [7] or by passing the leakage path by using passive elements [8], [9].

In this paper, targeting ac microgrid, a family of Active Virtual Ground (AVG) converters is presented [10]-[15] and systematic analysis is carried out. Throughout the series, all of the grid-connected converters are in single-stage transformerless designs and support a wide range of coverage, including AC-DC, DC-AC, or bidirectional AC-DC designs. All the time, only one HF switch is required in each operation mode. Meanwhile, during circuit operation, a low-pass filter is always generated on the grid-side, which minimizes the HF current ripple on the grid-side and clamps the HF voltage ripple between the AC and DC sides. As a result, through the use of AVG converters, a highly efficient and low leakage current system is guaranteed, which can fully meet the use requirements 
TABLE I

ApPLiCATION OverVIEW In AC MirCogrid

\begin{tabular}{|c|c|c|c|c|c|c|c|}
\hline \multirow[b]{2}{*}{$\begin{array}{l}\text { Microgrid } \\
\text { Unit }\end{array}$} & \multirow[b]{2}{*}{ Interface } & \multirow[b]{2}{*}{ Application } & \multirow[b]{2}{*}{$\begin{array}{l}\text { Grid Connected } \\
\text { Example }\end{array}$} & \multicolumn{3}{|c|}{ Performance Requirement } & \multirow{2}{*}{$\begin{array}{c}\text { Possible } \\
\text { Transformerless } \\
\text { Front Stage }\end{array}$} \\
\hline & & & & $\begin{array}{l}\text { Galvanic } \\
\text { Isolation }\end{array}$ & $\begin{array}{l}\text { Leakage Current } \\
\text { Limitation }\end{array}$ & $\begin{array}{l}\text { Reactive Power } \\
\text { Delivery }\end{array}$ & \\
\hline \multirow{6}{*}{$\begin{array}{l}\text { Power } \\
\text { Consumer }\end{array}$} & \multirow{6}{*}{$\mathrm{AC} / \mathrm{DC}$} & $\begin{array}{l}\text { Information } \\
\text { Technology }\end{array}$ & $\begin{array}{l}\text { Mobile chargers, Server } \\
\text { powers and TVs, etc. }\end{array}$ & Yes & $\begin{array}{c}<3.5 \mathrm{~mA} \\
\text { IEC 60950-1 [32] }\end{array}$ & No & $\begin{array}{l}\text { Boost-type } \\
\text { Rectifiers }\end{array}$ \\
\hline & & Medical & $\begin{array}{l}\text { Surgery and dentist } \\
\text { equipment, etc. }\end{array}$ & Yes & $\begin{array}{c}<500 \mu \mathrm{A} \text { for Class I ME } \\
\text { Equipment, IEC 60601-1 [34] }\end{array}$ & No & $\begin{array}{l}\text { Boost-type } \\
\text { Rectifiers }\end{array}$ \\
\hline & & Household & $\begin{array}{l}\text { Refrigerator, IH Cooker, } \\
\text { and Conditioning, etc. }\end{array}$ & $\begin{array}{l}\text { Partially } \\
\text { (System with } \\
\text { SELV) }\end{array}$ & $\begin{array}{c}<3.5 \mathrm{~mA} \text { for } \\
\text { class I Appliance, IEC } \\
60335-1[5]\end{array}$ & No & $\begin{array}{l}\text { Boost-type or } \\
\text { Buck-boost-type } \\
\text { Rectifiers }\end{array}$ \\
\hline & & Lighting & $\begin{array}{l}\text { Electronic ballast, Street } \\
\text { Light and LED, etc. }\end{array}$ & $\begin{array}{l}\text { Partially } \\
\text { (System with } \\
\text { SELV) }\end{array}$ & $\begin{array}{l}<1 \text { mA for Class I Appliance, } \\
\text { IEC60598-1 [35] }\end{array}$ & No & $\begin{array}{l}\text { Boost-type or } \\
\text { Buck-boost-type } \\
\text { Rectifiers }\end{array}$ \\
\hline & & Machinery & Industrial equipment & No & $\begin{array}{c}>10 \text { mA Required Additional } \\
\text { Protective Bonding, } \\
\text { IEC06024-1 [36] }\end{array}$ & No & $\begin{array}{l}\text { Boost-type or } \\
\text { Buck-boost-type } \\
\text { Rectifiers }\end{array}$ \\
\hline & & Laboratories & $\begin{array}{l}\text { Measure equipment, } \\
\text { electrical equipment for } \\
\text { laboratories, etc. }\end{array}$ & No & $\begin{array}{l}<3.5 \mathrm{~mA} \text { at Single Fault } \\
\text { Condition, } \\
\text { IEC } 61010-1[37]\end{array}$ & No & $\begin{array}{l}\text { Boost-type or } \\
\text { Buck-boost-type } \\
\text { Rectifiers }\end{array}$ \\
\hline RES & $\mathrm{DC} / \mathrm{AC}$ & Solar & $\begin{array}{l}\text { String inverters, and } \\
\text { Micro-inverters }\end{array}$ & $\begin{array}{l}\text { Depend on } \\
\text { Region }\end{array}$ & $\begin{array}{c}<300 \mathrm{~mA} \text { for PV system, } \\
\text { IEC } 62109 \text { [4] and VDE } \\
0216-1-1[38]\end{array}$ & $\begin{array}{c}0.95 \\
>3.68 \text { KVA } \\
\text { VDE-AR-N 4105 [39] }\end{array}$ & $\begin{array}{l}\text { Buck-type and } \\
\text { Buck-boost type } \\
\text { Inverters }\end{array}$ \\
\hline \multirow{2}{*}{ ESS } & \multirow{2}{*}{$\begin{array}{c}4 \mathrm{Q} \\
\mathrm{AC} / \mathrm{DC}\end{array}$} & $\begin{array}{l}\text { Energy } \\
\text { Storage }\end{array}$ & $\begin{array}{l}\text { UPS, Back-up power, } \\
\text { and Energy storage, etc. }\end{array}$ & $\begin{array}{l}\text { Depend on } \\
\text { Usage }\end{array}$ & $\begin{array}{c}<3.5 \mathrm{~mA} \text { in UPS systems } \\
\text { IEC } 62040-1[40]\end{array}$ & Optional & 4Q Converters \\
\hline & & $\begin{array}{l}\text { EVs (V2G } \\
\text { and G2V) }\end{array}$ & $\begin{array}{l}\text { Home EV charger and } \\
\text { Charger station, etc. }\end{array}$ & Yes & $\begin{array}{l}<3.5 \mathrm{~mA} \text { for Class I Charger, } \\
\text { IEC 61851-1 [41] }\end{array}$ & Optional & 4Q Converters \\
\hline
\end{tabular}

of different applications in the local AC microgrid. According to the usages in the microgrid networks, the analyzed converters in the AVG family are classified into three different categories, which are converter design for power consumers, RESs, and ESSs. In this paper, a general selection recommendation for each application division is provided and a unified design guideline is presented. A set of 650 to $800 \mathrm{~W}, 120$ Vac laboratory prototype has been built to verify the advantage of the presented AVG converter family. All the experimental findings are in a good agreement with the theoretical knowledge.

\section{Review Application in Single-Phase Microgrid}

In order to form a 1PAC microgrid network, three key elements, i.e. power consumers, RESs, and ESSs, are required.

Power consumers are the traditional grid appliances that consume energy from the grid to drive for different power appliances. To effectively adapt the power from the microgrid, effective rectifier interfaces are always required. In a $1 \mathrm{P} \mathrm{AC}$ microgrid, power consumers are commonly appearing in our daily life, such as telecom power supply [16], [17], lighting systems [18], [19], and household equipment [20], [21], etc.

RESs, which are environment friendly, are the major power generation sources in a microgrid system to support the power demand to localized areas, such as residential buildings and industrial facilities. To convert renewable energy into the microgrid, effective inverter interfaces are always required. Solar energy [22]-[25] is one of the major energy sources in this area in $1 \mathrm{PAC}$ microgrid.
ESSs are another key element in the microgrid system. They are used as backup energy units and energy buffers in the microgrid system. The power interfaces for EESs need to have both rectifier capability and inverter capabilities, as well as the ability to maintain the quality of the grid through reactive power injection. As a result, in the ESSs category, an effective fourquadrant (4Q) converter interfaces are always required. In this branch, energy storage units [26], [27] are one of the typical examples. Meanwhile, the electric vehicle (EV) energy storage platform integrating with the vehicle-to-grid (V2G) concept [28] -[32] could be another suitable application.

In different applications, the performance requirements of the converters are also different. Regarding the major applications in the $1 \mathrm{P} \mathrm{AC}$ microgrids, the corresponding performance requirements and international standards, [4], [5], [33]-[41], are listed in Table I. One of the key requirement consisting in the system is safety which has a very high standardized requirement for each application design. As the 1P AC microgrid is more like a local grid or a low-voltage community grid network, public usage is always involved. Therefore, a lot of daily appliances also require to produce a safety extra-low voltage (SELV) point which can completely isolate from the grid side, and only allow low system leakage current to appear. Even though in some applications, galvanic isolation is not required, the leakage current is still required to maintain according to the international standards to avoid the danger of public users when touching the equipment enclosure chassis or casing.

In each branch, the selection of the type of converters is 


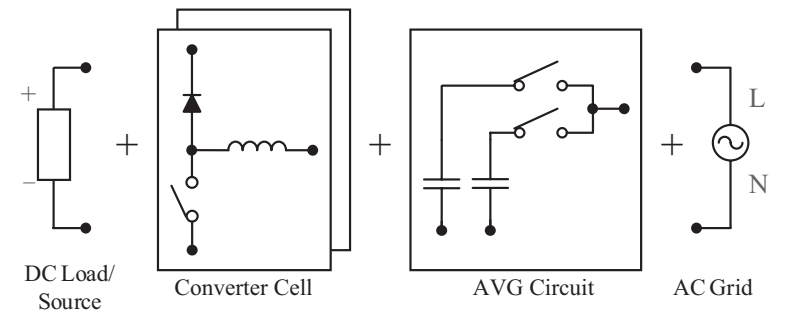

Fig. 2. Basic AVG converter blocks.

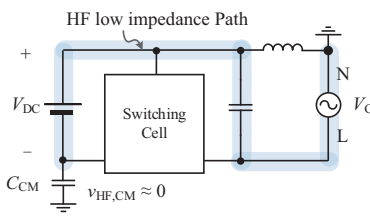

(a)

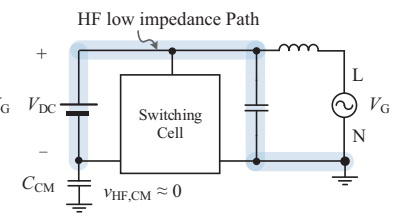

(b)
Fig. 3. Equivalent circuits of (a) positive and (b) negative half-line cycles of AVG buck-boost-type inverter with HF low impedance path indication.

highly depending on the application safety requirement. In the applications do no need for galvanic isolation, it can directly use a transformerless interface to do the power converting between the 1P AC microgrid and a DC appliance. Or, if galvanic isolation is needed, then a multi-stage interface is required. It will be at least a grid side interface together with a HF isolation converter design. Therefore, a wide range of converter design is required in the $1 \mathrm{P}$ AC microgrid. All of the applied converters should come with the basic requirement of low leakage current and high efficiency.

\section{Principle of Active Virtual Ground Technique}

The basic of AVG technique is a reconfigurable filter circuit, which consists of filter capacitors and bi-directional switches. As shown in Fig. 2, by combining the AVG circuit with two converter cells in a dedicated arrangement, an AVG converter will be formed. Those resultant AVG systems will feature with:

- Continuous grid current and small HF ripple.

- Low common-mode noise and low leakage current.

- Fully utilization of each magnetic components.

- A wide range of application coverages.

In each AVG converter, it consists of two switching cells, in which each of them includes a diode, a switch, and an inductor in each cell. They will take turns to handle the power conversion work at the positive and negative half-line cycles. At the same time, the pair of bi-directional switches in the AVG circuit is also switching alternatively under line frequency (LF) operation to result in different combinations of grid-side filters with the converter cells. As a result, a symmetric circuit is resultant in both positive and negative half-line cycles, where an example is given in Fig. 3.

The working principle of the AVG is to use a filter capacitor to set up a connection path between the DC bus terminal and the grid terminal. In the HF point of view, the impedance of the capacitor is at a relatively low value. Thus, in the HF domain, the potential difference between the two terminal becomes almost zero, and two terminals behaveas virtually connecting to each other. Under the alternative switching action in the AVG circuit, the filter capacitor keeps linking with both AC and DC terminals, and maintains a virtual connect path on between.

In Fig. 3, a capacitor $C_{\mathrm{CM}}$ is used to represent the circuit parasitic capacitor and to indicate the leakage path. In the HF analysis, both $\mathrm{AC}$ and DC sides are considered as a short circuit, which makes the AVG filter capacitor and $C_{\mathrm{CM}}$ becomes in a parallel relationship. Therefore, the HF ripple on the filter capacitor will be directly reflected in $C_{\mathrm{CM}}$ as well. In the design, as the potential difference between two terminal ends is clamped by the filter capacitor, only a small HF ripple voltage is induced on top of the capacitor. Thus, the system leakage current is also able to limit to a relatively small value.

In the resultant converters, there are always presented with two circuit inductors. In each half-line cycle, the role of both inductors is also different. One of them will act as a grid-side inductor and link with the filter capacitor to form a grid-side filter to limit the differential current in the grid. The other will be the inductor on the converter side and handle the energy conversion during the HF switching action. Their roles will be interchanged in every half-line cycle. With the AVG technique, the leakage current is eliminated by the virtual connection path separately. Therefore, different from the bypassing leakage path methodology [8], [9], all the time both inductors are always functional active and remain fully utilized during the system operation. Overall, the resulted converter family results with the characteristics of common-mode noise voltage and low differential-mode noise current.

Through the configuration in Fig. 2, various topology combinations are resultant, such as buck-type, boost-type, buckboost-type grid connecting converters, which are able to cover most of the review single-phase microgrid applications. Details of the prior-art are discussed in the coming section.

\section{Family of Active Virtual Ground}

Focusing on an AC microgrid network, a family of AVG converter is presented to cover the wide range of applications and is separated into three different sub-groups, which are the converters for power consumers, RESs and ESSs. In each branch, two different types of AVG topologies are proposed to cover different application requirements. Details of prior-art topologies are shown in Fig. 4 and a corresponding family tree is presented in Fig. 5.

\section{A. Design for Power Consumer}

According to EN 61000-3-2 [41], once the grid-connected power appliances are capable with more than $75 \mathrm{~W}$, a power factor correction (PFC) circuit is required. It is used to improve the real power delivery and to enhance the power quality in the grid. Accordingly, in this power consumers branch, two different types of AVG rectifiers are presented.

An AVG boost-type bridgeless PFC was presented in [10], which is shown in Fig. 4(a). It forms by two identical boosttype switching cells and an AVG circuit. The resultant topology takes the advantage of high efficiency characteristic from the bridgeless PFC but does not come with a high leakage current problem, where a single switch operates with $\mathrm{HF}$ at each half-line cycle and the AVG circuit clamp the noise in the system. Thus, a low noise and high efficient interface is always guaranteed.This topology is suitable for isolated type DC appliances, such as 


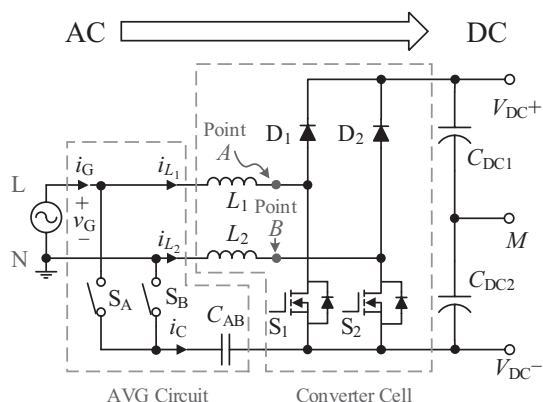

(a)

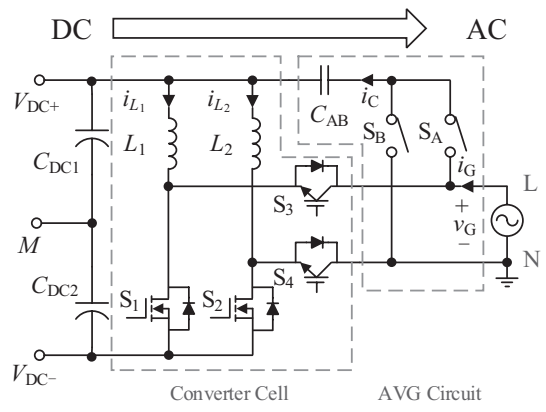

(d)

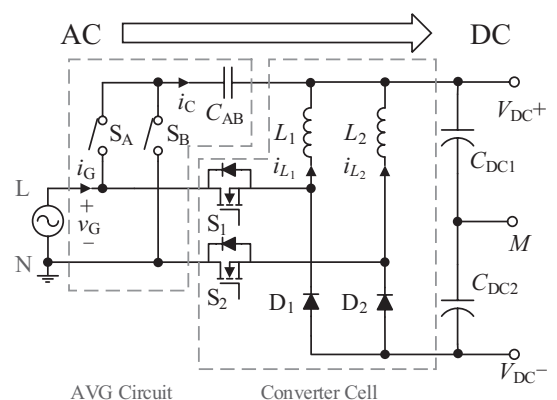

(b)

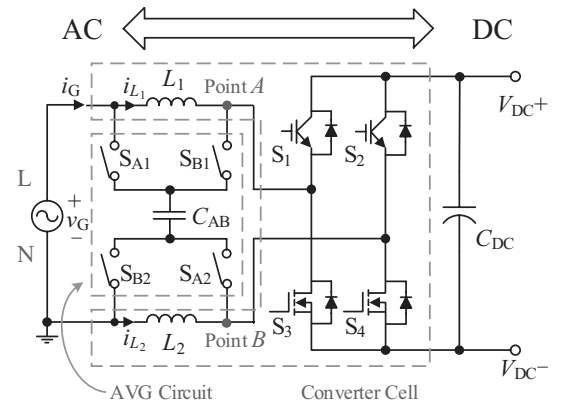

(e)

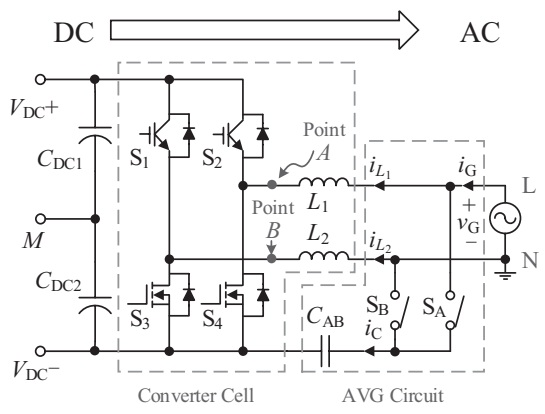

(c)

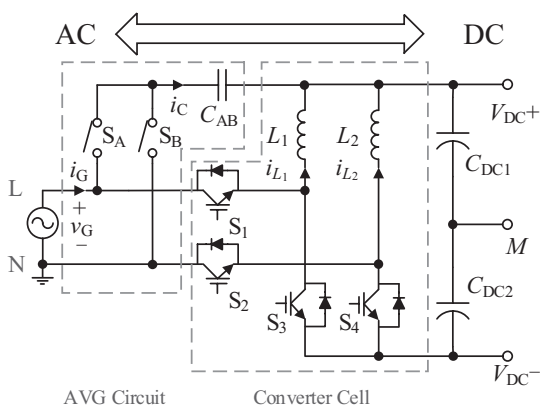

(f)

Fig. 4. AVG converter: (a) boost-type PFC [10], (b) buck-boost-type PFC [11], (c) buck-type VSI [12], (d) buck-boost-type VSI [13], (e) full-bridge VSC [14], and (f) 4Q buck-boost-type VSC [15].

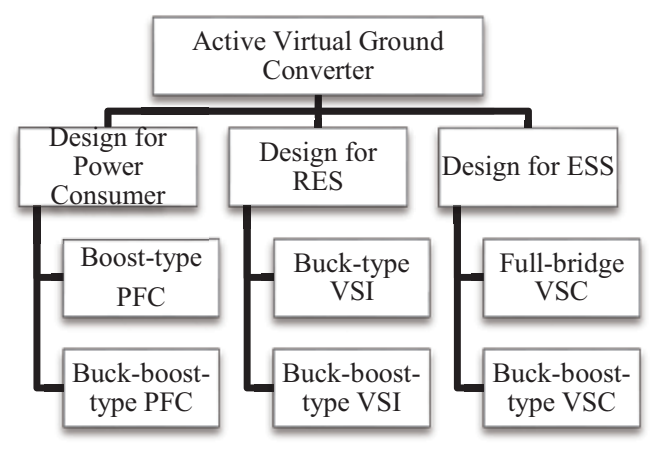

Fig. 5. Family tree of AVG converter.

devices in telecommunication, in house lighting power units, and household appliances. Generally, they act as a front stage step-up rectifier and follow by an isolated DC-DC converter. Under this approach, the system is able to feature with galvanic isolation and provides a safe design for public users.

Apart from the boost-type PFC, an AVG buck-boost-type bridgeless PFC was introduced in [11], which is shown in Fig. 4(b). It forms by two identical buck-boost-type switching cells and an AVG circuit. Like the boost-type PFC, the resultant buck-boost-type solution is also with bridgeless design and only requires one switch to operate with $\mathrm{HF}$ at each half-line cycle. In the meantime, low common mode noise is always guaranteed by the AVG design. This topology is suitable as a transformerless converter design on the non-isolated type DC power appliances, which provides an opportunity to increase the system power density by replacing a traditional two-stage system into a single- stage unit. Also, compared with the two-stage system, it provides an efficiency benefit in the low and middle power ranges. Uninterruptible power supplies, household DC machine units, and street lighting power units are its possible applications.

\section{B. Design for RES}

In residential or localized areas, solar energy is a common RES. To effectively convert the solar energy from the panel side to the AC network, there are three ways on the implementation, either through string inverters, micro-inverters, or power optimizers plus PV inverters. Accordingly, two different types of AVG inverters are presented in this RES branch.

An AVG buck-type voltage source inverter (VSI) was presented in [12], which is shown in Fig. 4(c). It forms by two identical buck-type switching cells and an AVG circuit. It is an inverter version of [10], where two more active switches are used and a different switching pattern is adopted. The possible use of modulation and control methods are not unrestricted. By using the switching scheme proposed in [12], the resultant buck-type VSI can maintain the advantages of low HF switching loss, and control the noise level within the standard value. This topology is suitable for solar inverter systems either with high panel voltage output or adopting with an front stage power optimizer. It can support the PV applications in various power levels, from low to high power ranges. If a low voltage ride through (LVRT) [42] feature is required, this VSI design can directly modify into the AVG full-bridge voltage source converter (VSC) to support the reactive power delivery at the under-voltage scenario.

Apart from the buck-type VSI, an AVG buck-boost-type VSI was given in [13], which is shown in Fig. 4(d). It forms by two 
identical buck-boost-type switching cells and an AVG circuit. Like the buck-type VSI, the resultant buck-boost-type solution is also in a single-stage design and only requires one switch to operate with $\mathrm{HF}$ at each half-line cycle. In the meantime, the potential between the AC grid and the DC terminal is clamped by the AVG capacitor. Thus, a low leakage current performance is always guaranteed. This topology is suitable for transformerless solar inverter systems, such as string inverters in solar systems. It can achieve efficient power conversion under a wide range of PV panel input and maintains a high-quality AC grid power in a stable manner. In the low and medium power ranges, it will have a significant efficiency advantage over others. For a high power system, interleaved design can be considered to extend the efficiency advantage of this topology. Similarly, this AVG buck-boost-type VSI is also able to modify into a buck-boosttype VSC to support the LVRT feature.

\section{Design for ESS}

In the energy storage unit, in order to support various system possibilities, a 4Q design is needed. Accordingly, two different types of AVG VSC are presented in this ESS branch.

An AVG full-bridge VSC was introduced in [14], which is shown in Fig. 4(e). It includes a full-bridge converter and an AVG circuit. In this design, in order to effectively claim the common-mode voltage in each quadrant of operation, an $\mathrm{H}$ shape AVG circuit is applied. With the use of a unipolar switching scheme, the whole 4Q operation is able to complete by two HF switches. Moreover, due to the freewheeling path is not set in the HF switches, a wide range of device combination is able to be produced. Overall, a high efficiency and low noise 4Q full-bridge VSC is able to be produced. The EV charging system is a typical application, where system isolation and output step down are handled by the second-stage isolated converter. Thus, the AVG full-bridge VSC is highly suitable to adopt as its gridconnected front stage to handle the effective power conversion between the AC grid and the internal DC bus.

Apart from the AVG full-bridge VSC, an AVG buck-boosttype VSC was presented in [15]. The topology structure is shown in Fig. 4(f) which will be similar to Fig. 4(d). However, in order to support the $4 \mathrm{Q}$ operation, all the main switches are required to operate under $\mathrm{HF}$ switching and to provide a fast recovery freewheeling path. It induces an efficiency reduction in the actual power delivery mode, and is lower than the AVC buck-boost VSI and AVG buck-boost PFC. However, it provides huge benefits for systems that require reactive power injection. Especially, in the transformerless type battery storage system, the presented solution is able to complete the actual power conversion and reactive power injection between the $\mathrm{AC}$ grid and the low-voltage battery cell within a single-stage circuit. Thus, this AVG buck-boost-type VSC is perfectly fitted for it.

\section{Design of Active Virtual Ground Converters}

All the described topologies in Fig. 4 are with identical circuit structures in both positive and negative half-line cycles. In both cases, they can also be simply into the basic converter switch

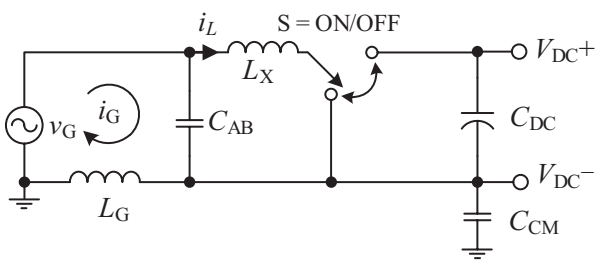

(a)

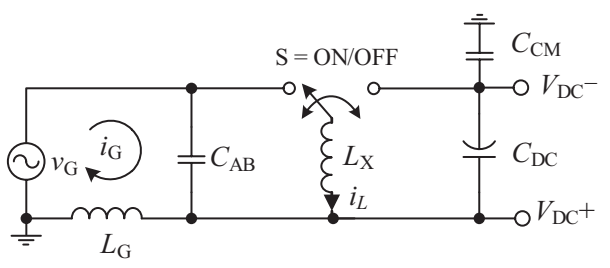

(b)

Fig. 6. Equivalent circuit of (a) boost-type and buck-type AVG converter designs, (b) buck-boost-type AVG converter designs at positive half-line cycle.

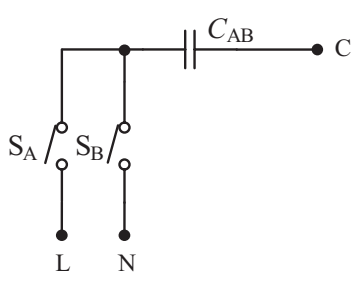

(a)

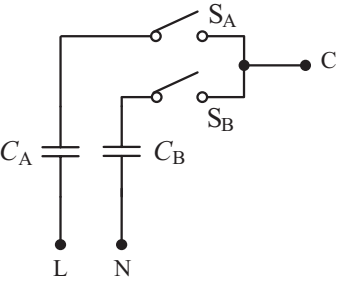

(b)

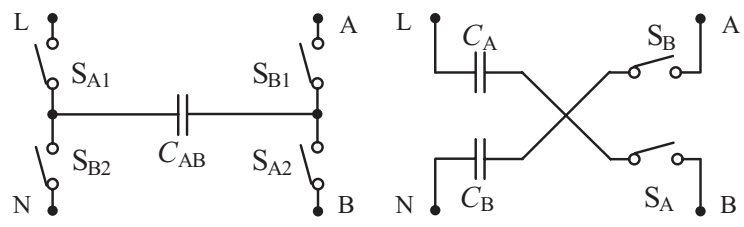

(c)

(d)

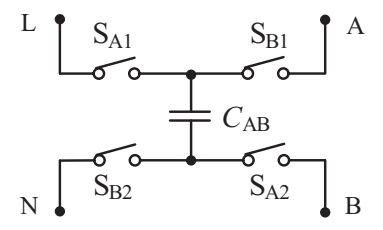

(e)

Fig. 7. Option in AVG circuit, (a) common source single capacitor, (b) common source split capacitor, (c) H shape, (d) X shape, and (e) 2Y shape.

unit circuit and grid-side filter circuit. They could be summarized into two types of equivalent circuit model, as shown in Fig. 6(a) and (b). The equivalent circuit of boost-type and buck-type AVG designs is shown in Fig. 6(a). The equivalent circuit of buckboost-type AVG designs is given in Fig. 6(b). Depending on the direction of power flow, the switching behavior will be different.

\section{A. Optional in AVG Circuit}

In the AVG circuit implementation, there is a variant of option, as shown in Fig. 7. Meanwhile, a combination summary is 
TABLE II

IMPLementaTion Options in AVG Converter Design

\begin{tabular}{|c|c|c|c|c|c|}
\hline \multirow[b]{2}{*}{ AVG Converter } & \multicolumn{5}{|c|}{ Type of AVG Connection } \\
\hline & $\begin{array}{l}\text { CS- Single } \\
\text { Capacitor }\end{array}$ & $\begin{array}{l}\text { CS- Split } \\
\text { Capacitor }\end{array}$ & X Shape & H Shape & $\begin{array}{l}2 \mathrm{Y} \\
\text { Shape }\end{array}$ \\
\hline Boost-type PFC & $\checkmark$ & $\checkmark$ & $\checkmark$ & $\checkmark$ & $\checkmark$ \\
\hline $\begin{array}{l}\text { Buck-boost-type } \\
\text { PFC }\end{array}$ & $\checkmark$ & $\checkmark$ & $\mathrm{X}$ & $\mathrm{X}$ & $\mathrm{X}$ \\
\hline Buck-type VSI & $\checkmark$ & $\checkmark$ & $\checkmark$ & $\checkmark$ & $\checkmark$ \\
\hline $\begin{array}{l}\text { Buck-boost-type } \\
\text { VSI }\end{array}$ & $\checkmark$ & $\checkmark$ & $\mathrm{X}$ & $\mathrm{X}$ & $\mathrm{X}$ \\
\hline Full-bridge VSC & $\mathrm{X}$ & $\mathrm{X}$ & $\mathrm{x}$ & $\mathrm{X}$ & $\checkmark$ \\
\hline $\begin{array}{l}\text { Buck-boost-type } \\
\text { VSC }\end{array}$ & $\checkmark$ & $\checkmark$ & $\mathrm{X}$ & $\mathrm{x}$ & $\mathrm{X}$ \\
\hline
\end{tabular}

given in Table II.

In Fig. 7(a), it shows a "common source single capacitor" AVG circuit. This approach has the simplest in circuit structure and less component requirement in design, in which only one filter capacitor and two LF switches are required. Therefore, it is also the most common one in usage. The connection points " $\mathrm{L}$ " and "N" are referred to as the Line and Neutral terminals. The connection point " $\mathrm{C}$ " can be connecting to either positive DC, negative, or middle DC terminals in Fig. 4, which depends on the topology usages and applications required and will not cause any DC voltage imbalance issue. Such as in lighting systems, " $\mathrm{C}$ " would recommend connecting to the middle point of the DC link. In this way, when a large surge current appears in the input, the output capacitor can help to handle the large current flow.

In Fig. 7(b), it shows a "common source split capacitor" AVG circuit. Compared to "common source single capacitor", this approach has one more additional filter capacitor. Each capacitor branch handles a half-line cycle operation and no overlap period occurs between the two branches. Even both switches $\mathrm{S}_{\mathrm{A}}$ and $\mathrm{S}_{\mathrm{B}}$ fail and conduce at the same time, it will not cause the $\mathrm{AC}$ grid to be short-circuited. Therefore, a more stable converter structure can be produced. Meanwhile, it could be the lowest cost AVG version for the household appliances. As the device voltage stress in the AVG switches is kept at a relatively low level, thus, the cost in the semiconductor device can be minimized. Secondly, by connecting " $\mathrm{C}$ " to the negative DC bus, all the AVG switches are a reference to one point. Therefore, the isolation feature in the gate drive and sensing circuits can be eliminated to further reduce the system cost.

In Fig. 7(c) to (e), it shows the variants of the AVG circuit, which is an "X shape", "H shape" and " $2 \mathrm{Y}$ shape" AVG circuits, respectively. Two connection points connect with " $\mathrm{L}$ " and "N", and the other two connection points point to the connection point "A" and "B", as shown in Fig. 4. Compared to the common source design, this group of variants provides a high degree of flexibility on implementation. Especially in boost-type PFC and buck-type VSI, they are easily adding into the existing converter and no need to make a circuit connection to the DC bus. However, more components are required. Among them, " $2 \mathrm{Y}$ Shape" is the only option to realize the AVG full-bridge VSC and to generate a smooth filter capacitor voltage under reactive power delivery. "X Shape" is the one closed to the "common source split capacitor", in which two independent branches to handle half-line cycle operation. Thus, their outcomes would be similar to each other.

\section{B. General Design Guideline}

According to the equivalent circuits shown in Fig. 6, the circuit behavior is studied and a group of design relative equations is derived, as shown in Table III.

For the design of the passive components, leakage migration and filter performance are two major concerns. In Fig. 8, a design flow chart is given, in which it starts directly from the leakage migration requirements to select the capacitor value, and then follows by the filtering requirement and power conversion performance needs to select the inductor values. In the filter circuit, the majority function of the applied capacitor is to filter the HF current ripple of the resultant topologies. Thus, the ceramic capacitors would be one of the best options, as it has a nonpolarized feature and low parasitic value. During the operation, it is always coupling between the AC and DC sides. Accordingly, its voltage and current rating can be formulated as (4) and (5). In the inductor selection, the weighting of the energy conversion function will be much higher than the filter function. Therefore, amorphous metal cores and powder cores are two of the possible options, as they are with high core saturation limit and the permeability of them is less dependent on temperature. The current rating of the converter inductor can be defined by (1) and (2). As an energy conversion element, the first concern will be the current ripple resultant in the system. However, different from the traditional topology, benefiting from the AVG technique, the resultant AVG converter topology is always with low grid-side current ripple. Therefore, it leaves a lot of fo room to release the ripple current requirement in the traditional approach to reduce the size of the required inductor but keep maintaining a relatively small grid-side inductor current ripple at the same time. After selecting a suitable inductor value, the resultant filtering range will be checked for suitability for the target system. Normally, we suggest that the filter cut-off frequency should be 5 times smaller than the targeting switching frequency. The AVG circuit will be finished after all the requirements are met. So that an effective AVG converter is guaranteed.

Taking a buck-boost-type VSI as an example, the target application is defined as a $650 \mathrm{~W} 120$ Vac PV inverter and with a $100 \mathrm{nF}$ parasitic capacitor [43]. First of all, from (1), (2), and the given power rating, $20 \mathrm{~A}$ is the determined maximum inductor current rating. Secondly, by inputting the $300 \mathrm{~mA}$ leakage requirement [4], the preset parasitic capacitor value, and the determined maximum inductor current into (6), a suitable capacitor value can be found. With a suitable buffer on the design, a $6.6 \mu \mathrm{F}$ is selected. Thirdly, By setting the current ripple of the grid-side and converter-side inductors to $5 \%$ and $30 \%$ of the maximum rated value, respectively, an inductor of 0.78 $\mathrm{mH}$ is determined. According to the selected filter element, the outcome filter frequency is $2.18 \mathrm{kHz}$ which is 9 times lower 
TABLE III

List of System Design Equations

\begin{tabular}{|c|c|c|c|}
\hline & Boost-type and Buck-type AVG Converter & Buck-boost-type AVG Converter & Eq. \\
\hline $\begin{array}{l}\text { Inductor Fundamental } \\
\text { Current, } i_{\mathrm{L}}\end{array}$ & $i_{\mathrm{L}}(t)=\frac{2 \cdot P_{\mathrm{O}}}{V_{\mathrm{G}} \cdot \cos \theta} \sin (\omega t+\theta)$ & $i_{\mathrm{L}}(t)=\frac{2 \cdot P_{\mathrm{O}}}{V_{\mathrm{G}} \cdot \cos \theta} \sin (\omega t+\theta) \cdot \frac{V_{\mathrm{DC}}+V_{\mathrm{G}}|\sin \omega t|}{V_{\mathrm{DC}}}$ & (1) \\
\hline Inductor Current Ripple, $\Delta i_{\mathrm{L}}$ & $\Delta i_{\mathrm{L}}(t)=\frac{V_{\mathrm{G}}|\sin \omega t|}{V_{\mathrm{DC}}} \cdot \frac{V_{\mathrm{DC}}-V_{\mathrm{G}}|\sin \omega t|}{L \cdot f_{\mathrm{SW}}}$ & $\Delta i_{\mathrm{L}}(t)=\frac{V_{\mathrm{DC}} \cdot V_{\mathrm{G}}|\sin \omega t|}{\left(V_{\mathrm{DC}}+V_{\mathrm{G}}|\sin \omega t|\right) \cdot L \cdot f_{\mathrm{SW}}}$ & (2) \\
\hline Grid Current Ripple, $\Delta i_{\mathrm{G}}$ & $\Delta i_{\mathrm{G}}(t)=\frac{V_{\mathrm{G}}|\sin \omega t|}{V_{\mathrm{DC}}} \cdot \frac{V_{\mathrm{DC}}-V_{\mathrm{G}}|\sin \omega t|}{16 \pi \cdot C_{\mathrm{AB}} \cdot L^{2} \cdot f_{\mathrm{SW}}{ }^{2}}$ & $\Delta i_{\mathrm{G}}(t) \approx \frac{P_{\mathrm{O}} \cdot|\sin \omega t \cdot \sin (\omega t+\theta)|}{4 \cdot\left(V_{\mathrm{DC}}+V_{\mathrm{G}}|\sin \omega t|\right) \cdot L \cdot C_{\mathrm{AB}} \cdot f_{\mathrm{SW}}{ }^{2}}$ & (3) \\
\hline Voltage Filter Capacitor, $v_{\mathrm{CAB}}$ & $v_{\mathrm{CAB}}(t) \approx V_{\mathrm{G}}|\sin \omega t|$ & $v_{\mathrm{CAB}}(t) \approx V_{\mathrm{G}}|\sin \omega t|$ & (4) \\
\hline $\begin{array}{l}\text { Capacitor Current Ripple, } \\
\Delta v_{\mathrm{CAB}}\end{array}$ & $\Delta i_{\mathrm{CAB}}(t)=\frac{V_{\mathrm{G}}|\sin \omega t|}{V_{\mathrm{DC}}} \cdot \frac{V_{\mathrm{DC}}-V_{\mathrm{G}}|\sin \omega t|}{L \cdot f_{\mathrm{SW}}}$ & $\begin{array}{c}\Delta i_{\mathrm{CAB}}(t)=\frac{1}{2} \frac{V_{\mathrm{DC}} \cdot V_{\mathrm{G}}|\sin \omega t|}{\left(V_{\mathrm{DC}}+V_{\mathrm{G}}|\sin \omega t|\right) \cdot L \cdot f_{\mathrm{SW}}}+\frac{2 \cdot P_{\mathrm{O}}}{V_{\mathrm{G}} \cdot \cos \theta} \sin (\omega t \\
+\theta) \cdot \frac{V_{\mathrm{DC}}+V_{\mathrm{G}}|\sin \omega t|}{V_{\mathrm{DC}}}\end{array}$ & (5) \\
\hline $\begin{array}{l}\text { Common-mode Leakage } \\
\text { Current, } i_{\mathrm{CM}}\end{array}$ & $i_{\mathrm{CM}, \mathrm{MAX}}(t)=\frac{1}{2} \frac{C_{\mathrm{CM}}}{C_{\mathrm{AB}}+C_{\mathrm{CM}}} \Delta i_{\mathrm{L}}(t)$ & $i_{\mathrm{CM}, \mathrm{MAX}}(t)=\frac{V_{\mathrm{G}}|\sin \omega t|}{V_{\mathrm{DC}}+V_{\mathrm{G}}|\sin \omega t|} \cdot \frac{C_{\mathrm{CM}}}{C_{\mathrm{AB}}+C_{\mathrm{CM}}} i_{\mathrm{L}, \mathrm{MAX}}(t)$ & (6) \\
\hline Filter Resonant Frequency, $f_{\mathrm{r}}$ & $f_{\mathrm{r}}=\frac{\sqrt{2}}{\pi \sqrt{L \cdot C_{\mathrm{AB}}}}$ & $f_{\mathrm{r}}=\frac{1}{2 \pi \sqrt{L \cdot C_{\mathrm{AB}}}}$ & (7) \\
\hline
\end{tabular}

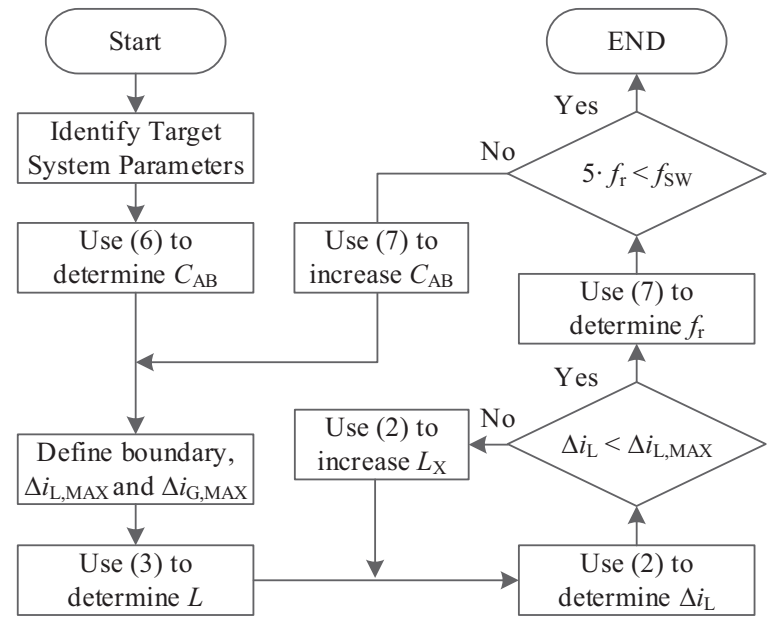

Fig. 8. AVG circuit design flow chart.

than the $20 \mathrm{kHz}$ target switching frequency. Thus, the AVG filter element design is completed.

For the design of the semiconductor switches, loss and costeffectiveness are two major concerns. Three different types of devices are required. The first type is AVG switches, where they are using to handle the HF ripple current and are LF switching only. So, a group of slow action and low on-state resistance can be used. The second type is the LF main power switches, where their main channels are using to produce the return path or the diodes are using to produce the freewheeling action of the system. So, comparing with the first group, this time a higher current and voltage rating devices are required. In addition, a fast recovery diode is always required. The third type is the HF main power switches, where they are responsible for the power conversion activity of the system. Thus, semiconductors with high power ratings are always required, and the semiconductors should have a fast transient response to reduce energy loss

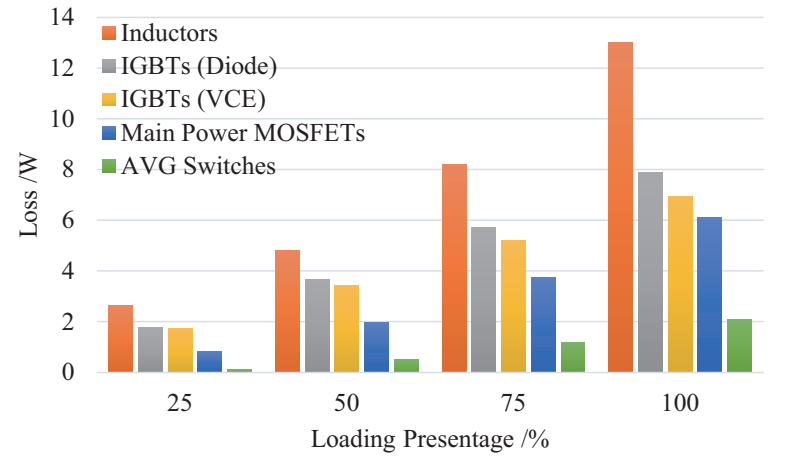

Fig. 9. Estimated loss breakdown of AVG buck-boost-type VSI.

during switching operations. Thus, a high efficiency PV interface is produced.

Keeping using a buck-boost-type VSI as an example, AVG switches could be implemented by two back-to-back connecting low power MOSFETs. The LF main power switches could be designed with high power IGBTs. The HF main power switches could be the fast response high power MOSFETs. An estimated loss breakdown of a 130 Vdc-120 Vac-650 W AVG buck-boosttype VSI is given in Fig. 9 as a reference.

\section{EXPERIMENTAL VERIFICATION}

A set of 650 to $800 \mathrm{~W}$ laboratory prototype has been used to verify the performance of the AVG converter family. The applied AC grid voltage is $120 \mathrm{~V} / 60 \mathrm{~Hz}$ and its THD is less than $0.1 \%$. In Fig. 10, it shows the experimental waveforms of four different AVG converter topologies, including (a) boost-type PFC design, (b) buck-boost-type PFC design, (c) buck-boost-type VSI design, and (d) full-bridge converter design, in which the applied semiconductors and passive components are summarized in Table IV and Table V, respectively. In addition, a performance summary is given in Table VI, where all the quality data were 


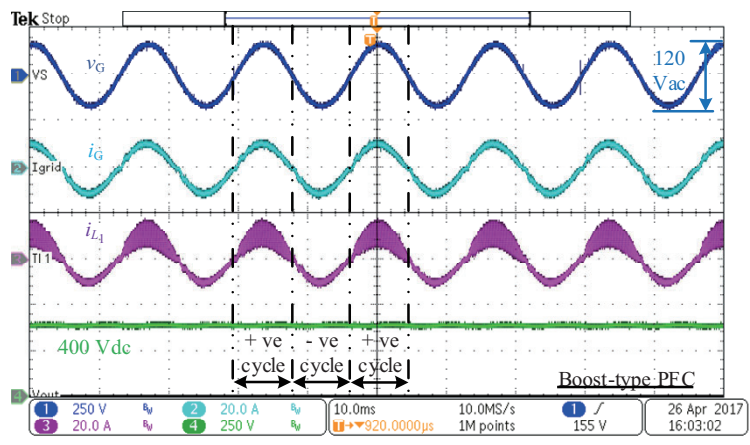

(a)

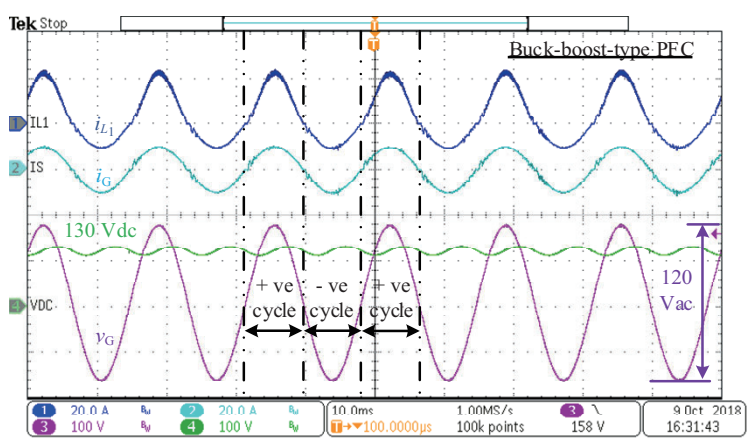

(b)

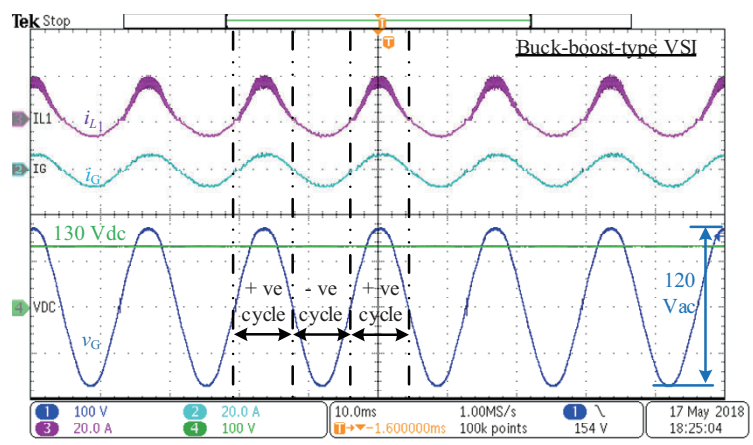

(c)

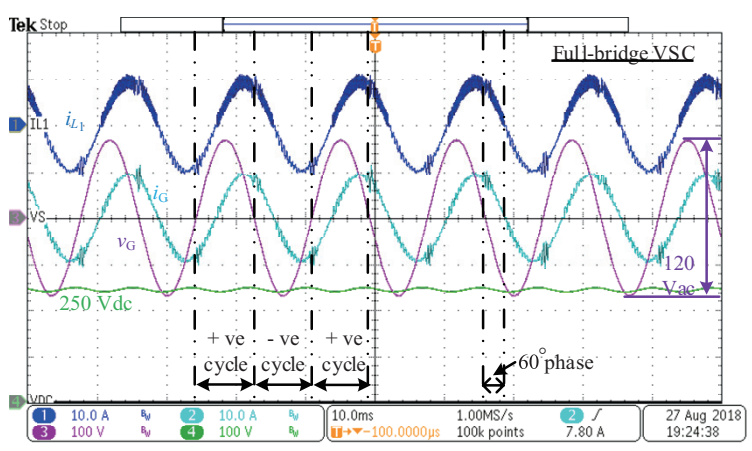

(d)

Fig. 10. Experimental results of (a) boost-type PFC, (b) buck-boost-type PFC, (c) buck-boost-type VSI and (d) full-bridge VSC.

experimentally measured by the power analyzer YOKOGAWAWT1800.

In the designed AVG converters, it maintained only one switch in HF operation in each state. The AVG circuit was a
TABLE IV

List OF SeMiconductors in the Prototypes

\begin{tabular}{lccc}
\hline \hline AVG Converter & AVG Switches & HF Switches & LF Switches \\
\hline Boost-type PFC & IPW60R125C6 & IPW60R070C6 & IKW20N60H3 \\
Buck-boost-type PFC & IPW60R070C6 & IPW60R080P7 & GP2D020A060B \\
Buck-boost-type VSI & IPW60R070C6 & IPW60R070P6 & STGW30H60DFB \\
Fultbridge VSC & STB46NF30 & IPW60R070C6 & IKW20N60H3 \\
\hline \hline
\end{tabular}

TABLE V

List of Passive Components in the Prototypes

\begin{tabular}{lccc}
\hline \hline AVG Converter & $L_{1} \& L_{2}$ & $C_{\mathrm{AB}}$ & $C_{\mathrm{DC}}$ \\
\hline Boost-type PFC & $0.78 \mathrm{mH}$ & $3.3 \mu \mathrm{F}$ & $1.2 \mathrm{mF}$ \\
Buck-boost-type PFC & $0.78 \mathrm{mH}$ & $3.3 \mu \mathrm{F}$ & $0.94 \mathrm{mF}$ \\
Buck-boost-type VSI & $0.78 \mathrm{mH}$ & $6.8 \mu \mathrm{F}$ & $1.9 \mathrm{mF}$ \\
Fultbridge VSC & $1.2 \mathrm{mH}$ & $3.3 \mu \mathrm{F}$ & $1.2 \mathrm{mF}$ \\
\hline \hline
\end{tabular}

TABLE VI

Performance Summary of AVG Converters

\begin{tabular}{|c|c|c|c|c|}
\hline \multirow[b]{2}{*}{ AVG Converter } & \multicolumn{4}{|c|}{ System Performance } \\
\hline & Power Factor & $\begin{array}{l}\text { Max. Current } \\
\text { THD }\end{array}$ & $\begin{array}{c}\text { Max. } \\
\text { Efficiency }\end{array}$ & $\begin{array}{l}\text { Leakage } \\
\text { Current }\end{array}$ \\
\hline Boost-type PFC & 0.996 & $3.48 \%$ & $96.20 \%$ & $\begin{array}{l} \pm 1.5 \mathrm{~mA} \\
\text { @ } 470 \mathrm{pF}\end{array}$ \\
\hline $\begin{array}{l}\text { Buck-boost-type } \\
\text { PFC }\end{array}$ & 0.991 & $4.93 \%$ & $96.8 \%$ & $\begin{array}{c} \pm 2 \mathrm{~mA} \\
\text { @ } 470 \mathrm{pF}\end{array}$ \\
\hline $\begin{array}{l}\text { Buck-boost-type } \\
\text { VSI }\end{array}$ & 0.984 & $4.71 \%$ & $95.7 \%$ & $\begin{array}{l} \pm 150 \mathrm{~mA} \\
\text { (a) } 100 \mathrm{nF}\end{array}$ \\
\hline Full-bridge VSC & N.A. & $4.91 \%$ & $96.98 \%$ & $\begin{array}{c} \pm 1 \mathrm{~mA} \\
\text { (a) } 330 \mathrm{pF}\end{array}$ \\
\hline
\end{tabular}

reconfigured grid-side circuit. Accordingly, in the positive halfline cycle, one inductor was forced to act as the converter-side inductor to process the power conversion. Another inductor became a grid-side inductor and form a grid-side filter with the AVG filter capacitor. In the negative half-line cycle, the AVG circuit is reconfigured and both inductor function was interchanged. Therefore, a grid-side filter was always found, which resulted in a low ripple grid current and minimized the HF common-mode noise.

In Fig. 10(a), it demonstrates the performance of an AVG boost-type PFC. The DC bus voltage and output power of the system were set to $400 \mathrm{Vdc}$ and $800 \mathrm{~W}$, respectively. Sinusoidal grid current was offered and the output voltage was regulated to the target DC value. Meanwhile, the HF current ripple at the grid-side was maintained in a relatively small value, which was much smaller than the converter-side current ripple. As a result, this efficient bridgeless boost-type PFC would be perfectly fitted to be the front stage of the information technology appliances or other applications that required galvanic isolation.

In Fig. 10(b), it demonstrates the performance of a singlestage AVG buck-boost-type PFC. The DC bus voltage and output power of the system were set to $130 \mathrm{Vdc}$ and $800 \mathrm{~W}$, 
respectively. Similar to the boost-type PFC, the system power factor was able to keep close to unity. But the difference is that a wide output range was achieved, which could be neither lower nor higher than the peak of the input voltage. Also, a continuous grid current was always offered in the described topology which is different from traditional buck-boost-type systems. Thus, more room was left for the design of the input EMI filter at the product level. Overall, those applications without galvanic isolation requirements are very suitable for it such as street light solutions and household appliances that without the do not require SELV.

In Fig. 10(c), it demonstrates the performance of an AVG buck-boost-type VSI. The DC bus input voltage and output power of the system were set to $150 \mathrm{Vdc}$ and $650 \mathrm{~W}$, respectively. A sinusoidal grid current was guaranteed and stable system performance was produced. According to the buck-boost circuit feature, the input voltage was able to vary within a wide voltage range. Thus, in the PV applications, the entire range of panel output can be covered and an efficient energy transmission can be achieved in whatever situations. Also, as shown in Fig. $10(\mathrm{c})$, the converter-side current was always higher than the gridside current. Thus, a pair of high saturation cores was required.

In Fig. 10(d), it demonstrates the performance of an AVG full-bridge VSC. The DC bus input voltage and output power of the system were set to $200 \mathrm{Vdc}$ and $800 \mathrm{~W}$, respectively. In Fig. 10(d), it shows the ability of reactive power injection, where the current was lagging the voltage with 60 degrees. In the $4 Q$ operation, the benefit of the AVG technique was retained. Both inductor function remained interchanged once during the halfline voltage cycle and only one switch was in HF operation at each state. Hence, a four-quadrant operation, low noise, and high-efficiency performance was realized in a single-stage converter. It is highly suitable for the fuel cell charging system.

All of the results were matched with the theoretical expectations. Under proper system controls, the power factors of the resulted interface were kept high than 0.98 and much higher than the 0.9 power factor requirement in IEC 61000-3-2 [44]. Also, the resultant current THDs were always within 5\% required according to IEEE 519 [45]. Thus, a sinusoidal grid current was always guaranteed and always synchronized with the grid voltage unless reactive power was required. In addition, benefited from the AVG technique, the resulted converters were able to maintain high system efficiency as highest as $96.98 \%$ and to control the leakage current into an acceptable range under different estimated application scenarios, such as telecom power, charger, and PV system, to fulfill the corresponding requirement in their product standards. Therefore, this series of converters have offered the ability to easily adopt various applications in a $1 \mathrm{PAC}$ microgrid.

\section{CONCLUSION}

The paper presented a family of Active Virtual Ground (AVG) converter topologies. The resultant converters included AC-DC, DC-AC, and bidirectional AC-DC designs in singlephase (1P) AC microgrids. Based on the specification of an AC microgrid system, the classification of AVG converters was generated and the targeting applications of each converter type were investigated. Accordingly, a unified design guideline has been produced and adopted by the entire AVG converter series. Through the equivalent circuit model, the core concept of AVG technique was evaluated and its common-mode migration technique was demonstrated. Overall, the resultant topology family was with low common-mode noise, singlestage structure, and stable in performance. The performance of the AVG converter family was demonstrated by experimental results. There is a good agreement between the concept and the experimental results.

\section{REFERENCES}

[1] Y. Yang, Q. Jia, G. Deconinck, X. Guan, Z. Qiu, and Z. Hu, "Distributed coordination of EV charging with renewable energy in a microgrid of buildings," in IEEE Transactions on Smart Grid, vol. 9, no. 6, pp. 62436264, May 2018.

[2] R. Atia and N. Yamada, "Sizing and analysis of renewable energy and battery systems in residential microgrids," in IEEE Transactions on Smart Grid, vol. 7, no. 3, pp. 1204-1213, May 2016.

[3] Y. Zhou and C. N. M. Ho, "A review on Microgrid architectures and control methods," in Proceeding of 2016 IEEE 8th International Power Electronics and Motion Control Conference (IPEMC-ECCE Asia), May 2016, pp. 3149-3156.

[4] Safety of Power Converters for Use in Photovoltaic Power SystemsPart 1: General Requirement, IEC Standard 62109-1: 2007, 2007.

[5] Household and Similar Electrical Appliances - Safety - Part 1: General Requirements, IEC Standard 60335-1: 2010, 2010.

[6] M. Victor, F. Greizer, S. Bremicker, and U. Hübler, "Method of converting a direct current voltage from a source of direct current voltage, more specifically from a photovoltaic source of direct current voltage, into a alternating current voltage," US Patent, No. US7411802 B2, Aug. $12,2008$.

[7] H. Schmidt, C. Siedle, and J. Ketterer, "DC/AC converter to convert direct electric voltage into alternating voltage or into alternating current," US Patent, No. US7046534 B2, May 16, 2006.

[8] M. Soldano and B. Lu, "EMI noise reduction circuit and method for bridgeless PFC circuit," US Patent, No. US7215560 B2, May 8, 2007.

[9] V. Bist and B. Singh, "An adjustable-speed PFC bridgeless Buck-Boost converter-fed BLDC motor drive," in IEEE Transactions on Industrial Electronics, vol. 61, no. 6, pp. 2665-2677, Dec. 2013.

[10] C. N. M. Ho, R. T. H. Li, and K. K. M. Siu, "Active virtual groundBridgeless PFC topology," in IEEE Transactions on Power Electronics, vol. 32, no. 8, pp. 6206-6218, Aug. 2017.

[11] K. K. M. Siu and C. N. M. Ho, "Manitoba rectifier - Bridgeless BuckBoost PFC," in IEEE Transactions on Power Electronics, vol. 35, no. 1, pp. 403-414, Jan. 2020.

[12] R. T. H. Li, C. N. M. Ho, and E. Chen, "Active virtual ground- Singlephase transformerless grid-connected voltage source inverter topology," in IEEE Transactions on Power Electronics, vol. 33, no. 2, pp. 13351346, Feb. 2018.

[13] C. N. M. Ho and K. K. M. Siu, "Manitoba inverter-Single-phase single-stage Buck-Boost VSI topology," in IEEE Transactions on Power Electronics, vol. 34, no. 4, pp. 3445-3456, Apr. 2019.

[14] K. K. M. Siu, C. N. M. Ho, and R. T. H. Li, "A four-quadrant singlephase grid-connected converter with only two high frequency switches," in IEEE Transactions on Industrial Electronics, Early Access.

[15] N. M. Ho and K. M. Siu, "Bi-directional bridgeless Buck-Boost converter," US Patent Application, No. US2018115256 B2, Aug. 13, 2019.

[16] L. Huber, Y. Jang, and M. M. Jovanovic, "Performance, evaluation of bridgeless PFC boost rectifiers," in IEEE Transactions on Power Electronics, vol. 23, no. 3, pp. 1381-1390, May 2008.

[17] F. C. Lee, Q. Li, Z. Liu, Y. Yang, C. Fei, and M. Mu, "Application of GaN devices for $1 \mathrm{~kW}$ server power supply with integrated magnetics," in CPSS Transactions on Power Electronics and Applications, vol. 1, no. 1, 
pp. 3-12, Dec. 2016.

[18] P. Fang and Y. Liu, "Energy channeling LED driver technology to achieve flicker-free operation with true single stage power factor correction," in IEEE Transactions on Power Electronics, vol. 32, no. 5, pp. 3892-3907, May 2015.

[19] S. T. S. Lee, H. S. H. Chung, and S. Y. R. Hui, "A novel electrode power profiler for dimmable ballasts using DC link voltage and switching frequency controls," in IEEE Transactions on Power Electronics, vol. 19, no. 3, pp. 847-853, May 2004.

[20] V. Bist and B. Singh, "An adjustable-speed PFC bridgeless Buck-Boost converter-fed BLDC motor drive," in IEEE Transactions on Industrial Electronics, vol. 61, no. 6, pp. 2665-2677, Dec. 2013.

[21] E. Jang, S. M. Park, D. Joo, H. M. Ahn, and B. K. Lee, "Feasibility study on all metal induction cooker systems considering topology and control," in Proceedings of 2018 IEEE Energy Conversion Congress and Exposition (ECCE), Portland, OR, USA, Sept. 2018, pp. 936-941.

[22] C. N. M. Ho, H. Breuninger, S. Pettersson, G. Escobar, L. A. Serpa, and A. Coccia, "Practical design and implementation procedure of an interleaved Boost converter using $\mathrm{SiC}$ diodes for PV applications," in IEEE Transactions on Power Electronics, vol. 27, no. 6, pp. 2835-2845, Jun. 2012.

[23] C. N. M. Ho, H. Breuninger, S. Pettersson, G. Escobar, and F. Canales, "A comparative performance study of an interleaved Boost converter using commercial $\mathrm{Si}$ and $\mathrm{SiC}$ diodes for $\mathrm{PV}$ applications," in IEEE Transactions on Power Electronics, vol. 28, no. 1, pp. 289-299, Jan. 2013

[24] T. K. S. Freddy, N. A. Rahim, W. P. Hew, and H. S. Che, "Comparison and analysis of single-phase transformerless grid-connected PV inverters," in IEEE Transactions on Power Electronics, vol. 29, no.10, pp. 5358-5369, Oct. 2014.

[25] S. B. Kjaer, J. K. Pedersen, and F. Blaabjerg, "A review of single-phase grid-connected inverters for photovoltaic modules," in IEEE Transactions on Industry Applications, vol. 41, no. 5, pp. 1292-1306, Oct. 2005.

[26] J. Kan, S. Xie, Y. Wu, Y. Tang, Z. Yao, and R. Chen, "Single-stage and Boost-voltage grid-connected inverter for fuel-cell generation system," in IEEE Transactions on Industrial Electronics, vol. 62, no. 9, pp. 54805490, Sept. 2015.

[27] B. M. Grainger, G. F. Reed, A. R. Sparacino, and P. T. Lewis, "Power electronics for grid-scale energy storage," in Proceedings of the IEEE, vol. 102, no. 6, pp. 1000-1013, Jun. 2014.

[28] Y. Ma, T. Houghton, A. Cruden, and D. Infield, "Modeling the benefits of vehicle-to-grid technology to a power system," in IEEE Transactions on Power Systems, vol. 27, no. 2, pp. 1012-1020, Jan. 2012.

[29] M. C. Kisacikoglu, M. Kesler, and L. M. Tolbert, "Single-phase on-board bidirectional PEV charger for $\mathrm{V} 2 \mathrm{G}$ reactive power operation," in IEEE Transactions on Smart Grid, vol. 6, no. 2, pp. 767-775, Mar. 2015.

[30] M. C. Kisacikoglu, B. Ozpineci, and L. M. Tolbert, "EV/PHEV bidirectional charger assessment for V2G Reactive power operation," IEEE Transactions on Power Electronics, vol. 28, no. 12, pp. 5717-5727, Dec. 2013

[31] Y. S. Kim, G. C. Parkm, J. H. Ahn, and B. K. Lee, "Hybrid PFC-inverter topology for bidirectional on board charger for range extended electric vehicle," in Proceedings of 2015 18th International Conference on Electrical Machines and Systems (ICEMS), Pattaya, Thailand, Oct. 2015 pp. 521-524.

[32] A. Ghosh, C. N. M. Ho, and K. K. M. Siu, "A manitoba converter based Bi-directional on-board charger for plug-in electric vehicles," in Proceedings of IEEE ECCE 2020, early access.

[33] Information Technology Equipment-Safety-Part 1: General Requirements, IEC Standard 60950-1: 2005, 2005.

[34] Medical Electrical Equipment-Part 1: General Requirements for Basic Safety and Essential Performance, IEC Standard 60601-1: 2005, 2005

[35] Luminaires-Part 1: General Requirements and Tests, IEC Standard 60598-1: 2006, 2006

[36] Safety of Machinery-Electrical Equipment of Machines-Part 1: General Requirements, IEC Standard 60204-1: 2005, 2005.

[37] Safety Requirements for Electrical Equipment for Measurement, Control, and Laboratory Use-Part 1: General Requirements, IEC Standard 610101: 2001, 2001.

[38] Automatic Disconnection Device Between a Generator and the Public Low-Voltage Grid, VDE Standard DIN-VDE Std. 0126-1-1, 2005.
[39] Power Generation System Connected to the Low-Voltage Distribution Network, VDE Standard VDE-AR-N 4105, 2011.

[40] Uninterruptible Power Systems (UPS)-Part 1-2: General and Safety Requirements for UPS Used in Restricted Access Locations, IEC Standard 62040-1-2: 2002, 2002.

[41] Electric Vehicle Conductive Charging System-Part 1: General Requirements, IEC Standard 61851-1: 2011, 2011.

[42] Y. Yang, F. Blaabjerg, and H. Wang, "Low-voltage ride-through of singlephase transformerless photovoltaic inverters," in IEEE Transactions on Industry Applications, vol. 50, no. 3, pp. 1942-1952, May-Jun. 2014.

[43] W. Chen, X. Yang, W. Zhang, and X. Song, "Leakage current calculation for PV inverter system based on a parasitic capacitor model," in IEEE Transactions on Power Electronics, vol. 31, no. 12, pp. 8205-8217, Dec. 2016.

[44] Electromagnetic Compatibility (EMC)-Part 3-2: Limits - Limits for Harmonic Current Emissions (equipment input current $\leq 16$ A per phase), IEC Standard 61000-3-2: 2001, 2001.

[45] IEEE Recommended Practice and Requirements for Harmonic Control in Electric Power Systems, IEEE Std 519-2014, 2014.

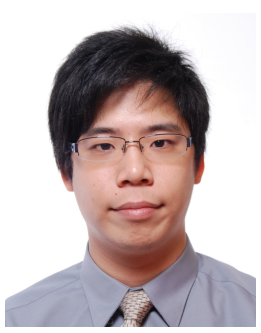

Ken King Man Siu received the B.Eng. and M.Eng. degree in electronic engineering from the City University of Hong Kong, Hong Kong, in 2010 and 2011, respectively, and the Ph.D. degree from University of Manitoba, Canada, in 2019.

From 2011 to 2015, he was a System Application Engineer at Infineon Technologies Hong Kong Ltd. to evaluate the latest power semiconductors and to develop their application platforms. He is currently a PostDoc Fellow in the Electrical and Computer Engineering Department at the University of Manitoba to research on gridconnected power electronics converters, microgrid technique, and renewable energy applications.

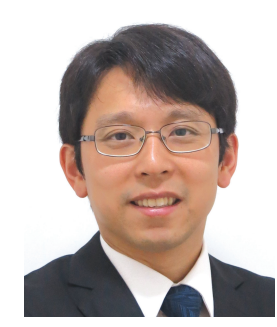

Carl Ngai Man Ho received the B.Eng. and M.Eng. double degrees and the Ph.D. degree in electronic engineering from the City University of Hong Kong in 2002 and 2007, respectively.

From 2002 to 2003, he was a Research Assistant at the City University of Hong Kong. From 2003 to 2005, he was an Engineer at e.Energy Technology Ltd., Hong Kong. In 2007, he joined ABB Switzerland. He has been appointed as Principal Scientist and he has led a research project team at ABB to develop Solar Inverter technologies. In October 2014, he joined the University of Manitoba in Canada, where he is currently an Associate Professor and Canada Research Chair in Efficient Utilization of Electric Power. He established the Renewable-energy Interface and Grid Automation (RIGA) Lab, the University of Manitoba, to research on Microgrid technologies, Renewable Energy interfaces, Real Time Digital Simulation technologies and demand-side control methodologies.

Dr. Ho is currently an Associate Editor of the IEEE Transactions on Power Electronics (TPEL) and the IEEE Journal of Emerging and Selected Topics in Power Electronics (JESTPE). He received the Second Place Winner for 2018 Prize Paper Awards of TPEL and he was the recipient of the Associate Editor Awards of JESTPE in 2018 and 2019. 